\title{
ESTRUTURA OU SENTIMENTO: A RELAÇÃO COM O ANIMAL NA AMAZÔNIA
}

Philippe Descola

A violência exercida contra os animais suscita uma reprovação crescente nas opiniões públicas ocidentais, uma reprovação que, freqüentemente, se torna ainda mais vivaz à medida que diminui a familiaridade com as vítimas. Nascida da indignação com os maus-tratos infligidos aos animais domésticos e de estimação, em uma época na qual burros e cavalos de fiacre faziam parte do ambiente cotidiano, atualmente, a compaixão nutre-se da crueldade a que estariam expostos seres com os quais os amigos dos animais, urbanos em sua mai oria, não têm nenhuma proximidade física: o gado de corte, pequenos e grandes animais de caça, os touros das touradas, as cobaias de laboratório e os animais fornecedores de pele, as baleias e as focas, as espécies selvagens ameaçadas pela caça predatória ou pela deterioração de seu habitat etc. As atitudes de simpatia para com os animais também variam, é claro, segundo as tradições culturais nacionais ${ }^{1}$. O horror legítimo ao sofrimento desnecessário, e mesmo a consciência de uma responsabilidade moral da espécie humana em assegurar o bem-estar dos seres com os quais ela partilha o planeta, são as principais motivações da sensibilidade ecológica nos países latinos. Em contrapartida, nos países do norte da Europa e nos Estados Unidos parecem ganhar terreno as teses mais radicais da deep ecology, que considera todos os componentes do meio natural como sujeitos de direitos homólogos aos humanos.

Todavia, na prática, as manifestações de simpatia pelos animais são ordenadas em uma escala de valor - geralmente inconsciente, mas totalmente explícita em alguns animal philosophers (Singer 1989; Regan 1983) - cujo ápice é ocupado pelas espécies percebidas como as mais próximas do homem em função de seu comportamento, fisiologia, faculdades cognitivas ou da capacidade que Ihes é atribuída de sentir emoções. Naturalmente, os mamíferos são os mais bem aquinhoados nessa hierarquia do interesse, e isso independentemente do meio onde vivem. 
Ninguém, assim, parece se preocupar com a sorte dos harenques ou dos bacalhaus, mas os golfinhos, que com eles são por vezes arrastados pelas redes de pesca, são estritamente protegidos pelas convenções internacionais. Quanto às medusas ou às tênias, nem mesmo os membros mais militantes dos movimentos de liberação animal parecem conceder-Ihes uma dignidade tão conseqüente quanto a outorgada aos mamíferos e aos pássaros.

O antropocentrismo, ou seja, a capacidade de se identificar com nãohumanos em função de seu suposto grau de proximidade com a espécie humana, parece assim constituir a tendência espontânea das diversas sensibilidades ecológicas contemporâneas, inclusive entre aqueles que professam as teorias mais radicalmente anti-humanistas. Tal atitude poderia lembrar a maneira como os povos pré-modernos representam suas relações com o ambiente: respeito pela natureza, atitude benévola para com as plantas e os animais ou cuidado de não pôr em perigo o equilíbrio dos ecossistemas foram erigi dos em atributos ostensivos das populações tribais, motivando em grande parte a simpatia que se Ihes dedica. Muitas organizações ecológicas, aliás, encontram uma fonte de inspiração nas visões de mundo dos índios da Amazônia ou da A mérica do Norte, convertidos pela mídia em símbolos da convivência harmoniosa com uma natureza cada vez mais ameaçada. A "mãe-terra" ou a "floresta sagrada" tornam-se conceitos genéricos da sabedoria étnica, mas seria bem difícil encontrar seu equivalente exato na maior parte dos povos a quem se atribui esse tipo de noção, pois tais transposições em mão dupla não estão livres de qüiproquó: freqüentemente, a retórica ecológica de alguns líderes indígenas exprime menos as concepções cosmológicas tradicionais - complexas e diversificadas, logo difíceis de formular no código simplificador de nossa economia política da natureza - do que um desejo de obter o apoio de organizações internacionais influentes, graças a um discurso facilmente reconhecível, e com a finalidade de conduzir lutas de reivindicação territorial (Descola 1985; Albert 1993). De selvagens, espera-se que tenham a linguagem de filhos da natureza; como eles deixariam de fazê-lo se, por aí, podem precaver-se da espoliação fundiária?

Por outro lado, tais convergências rapidamente encontram seus limites, especialmente quando certas formas locais de caça ferem a sensibilidade de militantes ecológicos pouco inclinados a encarar com indulgência os particularismos culturais que prejudicarem o bem-estar dos animais. Então, a caça de focas entre os Inuit ou aquela de grandes animais entre os Masai aparece como bárbara sobrevivência que uma boa dose de educação em proteção do ambiente permitiria erradicar. Pior ainda, as 
técnicas de subsistência adotadas por populações tribais podem ser percebidas por movimentos integristas de conservação da natureza como perturbadoras do equilíbrio de espaços protegidos, e não são raros os casos em que povos autóctones se defrontam com a interdição de seu acesso às fontes de reservas, erradamente ditas "naturais", já que foram eles que, por sua presença multissecular, contribuíram sutilmente para transformar sua ecologia. O antropocentrismo moderno, com efeito, é amplamente inconsciente e não combina com a idéia de que nosso ambiente é em grande parte antrópico, mesmo em regiões do mundo que parecem, como a A mazônia, ter conservado sua virgindade (Balée 1993).

Os mal-entendidos - aliás, por vezes, produtivos - entre minorias tribais e movimentos ecologistas devem-se ao fato de que, a despeito de similitudes superficiais e interesses táticos comuns, suas respectivas atitudes com relação à natureza são totalmente diferentes. Proteger os animais outorgando-Ihes direitos - ou impondo aos humanos deveres para com eles - é apenas estender a uma nova classe de seres os princípios jurídicos que regem as pessoas, sem colocar em causa de maneira fundamental a separação moderna entre natureza e sociedade. A sociedade é fonte do direito, os homens o administram, e é porque são condenadas as violências para com os humanos que as violências com relação aos animais se tornam condenáveis. Não é nada disso para numerosas sociedades pré-modernas, que, encarando os animais não como sujeitos de direito tutelado, mas como pessoas morais e sociais plenamente autônomas, se empenham tão pouco em estender-Ihes sua proteção, quanto julgam desnecessário velar pelo bem-estar de vizinhos distantes. Decidir tratar a natureza com respeito e benevolência supõe que a natureza exista - e também, sem dúvida, que tenha sido primeiramente maltratada. Quando a natureza não existe sob a forma de uma esfera autônoma, a relação com os animais só pode ser diferente da nossa, e a questão sobre matar um animal só pode se colocar em termos muito distintos daqueles que nos são familiares. É isso que um desvio pela A mazônia poderia permitir estabelecer.

Diferentemente do dualismo moderno que distribui humanos e nãohumanos em dois domínios ontológicos mais ou menos estanques, as cosmologias amazônicas estabelecem uma diferença de grau, não de natureza, entre os homens, as plantas e os animais. Os A chuar da Amazônia equatoriana, por exemplo, dizem que a maioria das plantas e dos animais possui uma alma (wakan) similar àquela dos humanos, uma faculdade que, ao assegurar-Ihes a consciência reflexiva e a intencionalidade, os inclui entre as "pessoas" (aents), torna-os capazes de experimentar emo- 
ções e permite-Ihes trocar mensagens com seus pares e com membros de outras espécies, e, assim, com os homens (Descola 1986; 1993a). Essa comunicação extralingüística é possibilitada pela aptidão atribuída à wakan de transmitir, sem mediação sonora, pensamentos e desejos à alma de um destinatário, modificando assim, por vezes à sua revelia, seu estado de espírito e seu comportamento. Para esse fim, os humanos dispõem de uma vasta gama de encantamentos mágicos, os anent, graças aos quais podem agir à distância sobre seus congêneres, e também sobre as plantas, os animais, assim como sobre os seres sobrenaturais e alguns artefatos. A harmonia conjugal, um bom entendimento com parentes e vizinhos, o sucesso na caça, a fabricação de uma cerâmica bonita ou um curare eficaz, uma roça com plantas variadas e viçosas, tudo isso depende das relações de conivência que os A chuar conseguirem estabelecer com uma variedade grande de interlocutores humanos e não-humanos, suscitando-Ihes disposições favoráveis por intermédio dos anent.

Os Achuar estabelecem certas distinções entre as entidades que povoam o mundo. A decorrente hierarquia dos objetos animados e inanimados não é, contudo, fundada sobre graus de perfeição do ser, sobre diferenças de aparência, ou sobre uma acumulação progressiva de propriedades intrínsecas. Ela se baseia na variação dos modos de comunicação, a qual é autorizada pela apreensão de qualidades sensíveis desigualmente distribuídas. Na medida em que a categoria das "pessoas" engloba espíritos, plantas e animais, todos dotados de uma alma, essa cosmologia não diferencia os humanos e os não-humanos; ela somente introduz uma escala de ordenação segundo os níveis de troca de informação tidos como possíveis. Os A chuar ocupam, como se poderia prever, o ápice da pirâmide: eles se vêem e se falam na mesma língua. O diálogo ainda é possível com os membros das outras tribos J ívaro que os cercam, e cujos dialetos são mais ou menos mutuamente inteligíveis, sem que, todavia, se possam excluir os mal-entendidos fortuitos ou deliberados. Com os brancos hispanófonos e as populações vizinhas de língua quéchua, e o antropólogo também, vê-se e fala-se simultaneamente, por menos que exista uma língua em comum; mas o domínio desta é geralmente imperfeito para aquele dos interlocutores que não a tem como língua materna, introduzindo-se assim a possibilidade de uma discordância semântica que tornará duvidosa a correspondência das faculdades que certifica a existência de dois seres sobre um mesmo plano do real. As distinções acentuam-se à medida que se distancia do domínio das "pessoas completas", penke aents, definidas, antes de tudo, por sua aptidão lingüística. Assim, os humanos podem ver as plantas e os animais que, quando pos- 
suem uma alma, são supostos perceberem os humanos; mas se os Achuar falam com eles graças aos encantamentos anent, não obtêm resposta senão por ocasião dos sonhos. Sucede o mesmo com os espíritos e com alguns heróis da mitologia: atentos ao que Ihes dizem, e geralmente invisíveis em sua forma primeira, só podem ser apreendidos em toda a sua plenitude no curso dos sonhos e transes induzidos pelos alucinógenos.

As "pessoas" aptas a se comunicarem são igualmente hierarquizadas em função do grau de perfeição das normas sociais supostas de regerem as diferentes comunidades nas quais elas se acham distribuídas. Alguns não-humanos são muito próximos dos A chuar por serem reputados de respeitar regras matrimoniais idênticas: é esse o caso dos Tsunki, espíritos do rio; de várias espécies de caça (macacos barrigudos, tucanos...); e de plantas cultivadas (a mandioca e o amendoim...). Em contrapartida, há seres que se comprazem na promiscuidade sexual e assim, constantemente, violam o princípio da exogamia; este é o caso do guariba ou do cão. 0 nível mais baixo da integração social é ocupado pelos solitários: os espíritos iwianch, encarnações das almas dos mortos que vagam abandonadas na floresta, ou então os grandes predadores como o jaguar ou a sucuri. Entretanto, por mais distanciados das leis da civilidade que possam estar, todos esses seres solitários são auxiliares dos xamãs, que os empregam para disseminar o infortúnio ou combater seus inimigos. Situados nas margens da cultura, esses seres nocivos não são de modo al gum selvagens, uma vez que os senhores aos quais servem não estão fora da sociedade.

Foram descritas em grande número cosmologias análogas para as regiões de floresta das terras baixas da América do Sul (ver Weiss 1975; Viveiros de Castro 1992; van der Hammen 1992; J ara 1991; Århem 1996; Grenand 1980; Renard-Casevitz 1991; Reichel-Dolmatoff 1976). Embora difiram em sua arquitetura interna, a característica comum a todas essas cosmologias é não separar o universo da cultura, que seria apanágio exclusivo dos humanos, do universo da natureza, no qual estaria incluído o restante das entidades que constituem o mundo. Os animais, e as plantas em menor medida, são aí percebidos como sujeitos sociais, dotados de instituições e de comportamentos perfeitamente simétricos àqueles dos homens. Além disso, os seres do cosmos definem-se menos por uma essência abstrata ou por uma faculdade particular (a presença ou ausência de linguagem, por exemplo, ou de consciência reflexiva e emoções) do que pelas posições que ocupam uns em relação aos outros, seja em função de características de seu metabolismo e, principalmente, de seu regime alimentar, seja em nome do tipo de comunicação em que são reputados capazes de se engajar. A identidade de cada um está, então, 
sujeita a mutações ou metamorfoses, já que fundada em campos de relações que variam segundo os tipos de percepção recíproca ou não recíproca atribuídos às entidades em jogo. Com efeito, cada espécie, em sentido amplo, é suposta apreender as outras espécies a partir de seus próprios critérios, de modo que em condições normais um caçador não verá, por exemplo, que sua presa animal se vê a si mesma como um humano, nem que ela o vê como um jaguar. Do mesmo modo, o jaguar vê o sangue que está bebendo como cauim; o macaco-aranha que o pássaro cassico acredita caçar é apenas um gafanhoto para o homem; e as antas de que a serpente pensa fazer sua presa principal na realidade são humanos. Graças à troca permanente das aparências gerada por esses deslocamentos de perspectiva, de boa-fé os animais se consideram dotados dos mesmos atributos culturais que os humanos: seus penachos são para eles coroas de pluma, sua pelagem uma roupa, seu bico uma lança ou suas garras facas. Cultivam roças, caçam, cozinham e se dedicam a rituais elaborados sob a direção de seus chefes e xamãs.

O hiper-relativismo perceptivo das cosmologias amazônicas engendra uma ontologia às vezes batizada de "perspectivismo" (Viveiros de Castro 1996), que nega aos humanos o ponto de vista de Sirius, afirmando que múltiplas visões de mundo podem conviver sem se contradizerem. Isso acarreta uma conseqüência ética importante: se os animais se vêem a si mesmos como pessoas empenhadas em atividades culturais, então não é possível negar-Ihes a humanidade que pretendem encarnar. Ao contrário do dualismo moderno, que desdobra uma multiplicidade de diferenças culturais sobre o fundo de uma natureza imutável, o pensamento ameríndio encara o cosmos inteiro como animado por um mesmo regime cultural, diversificado não tanto por naturezas heterogêneas quanto por modos diferentes de se apreender uns aos outros. Avalia-se toda a diferença para com o antropocentrismo ocidental, para quem alguns animais são dignos de proteção em nome de supostas faculdades muito próximas daquelas dos humanos: a sensibilidade, o altruísmo, o amor materno etc. Não se acha nada disso na A mazônia, onde o referente comum às entidades que povoam o mundo não é o homem enquanto espécie, mas a humanidade enquanto condição. Os animais são com certeza diferentes de nós em sua morfologia e em seu comportamento; contudo, a existência social que eles têm à nossa revelia é idêntica à nossa. Além disso, e como os mitos o atestam abundantemente, a condição inicial de uns e outros é cultural, não natural. Em um continuum original onde os humanos não se distinguem das plantas e dos animais, onde uns e outros falam, tocam música ou fazem cerâmica, uma série de aconteci- 
mentos catastróficos vai introduzir descontinuidades de aparência e de pontos de vista que condenarão os sujeitos do cosmos a uma certa forma de ilusão: doravante, salvo circunstâncias excepcionais, os homens não poderão mais ver os animais como congêneres ligados a um destino comum, e é então pelo trabalho da memória, alimentado pela tradição oral, que se poderá restabelecer uma continuidade que os sentidos não permitem mais averiguar. Por meio da ação ritual, pode-se ainda ultrapassar o solipsismo induzido pela diferenciação das faculdades sensíveis. Os ritos de caça e cultivo, a mediação do xamã nas relações com os espíritos que regem o destino dos animais de caça e dos peixes, a oniromancia, tudo isso atesta no cotidiano que plantas e animais são interlocutores legítimos; a despeito das aparências enganadoras, eles não vivem em um plano ontológico distinto daquele dos humanos.

Ora, os povos amazônicos tiram da caça e da pesca uma parte de sua alimentação. Quase todo dia os homens se confrontam, então, com a necessidade de fazer perecerem seres cobertos de penas, pêlos ou escamas, mas que com eles se parecem por vários atributos. Todos conhecem as circunstâncias dessa destruição. A morte dos animais e sua preparação não é dissimulada em recintos afastados da visão dos profanos, como ocorre entre nós atualmente, e todo mundo na A mazônia é familiarizado desde a mais tenra idade com aqueles corpos ainda quentes que se vão esfolar, estripar e cortar para cozinhar. Graças às intermináveis histórias de caça que os homens gostam de contar, todo mundo também sabe qual foi o comportamento do animal antes de morrer, o medo, a tentativa de fuga abortada, o sofrimento, as manifestações de aflição dos seus companheiros. Em suma, ninguém pode ignorar de que maneira um ser vivo se torna comida. Como esses povos podem então conciliar a violência que exercem cotidianamente contra os animais com a idéia de que esses seres são, de algum modo, humanos disfarçados? Como matar e alimentar-se de quase-semelhantes sem que tal incorporação do vivo pelo vivo apareça como uma forma de canibalismo? Tal contradição é muito mais forte que aquela que, eventualmente, nós próprios podemos experimentar na hora de consumir a carne. Os vegetarianos que se recusam à cumplicidade da destruição de uma vida, nem por isso se consideram congêneres dos animais que se abstêm de comer. Os mais decididos partidários da liberação animal decerto reconhecem direitos intrínsecos àqueles que M ichelet chamava nossos "irmãos inferiores", mas nenhum deles imagina que as vacas, os porcos ou as cobaias levem uma vida dupla e que, sob a ilusão de seu avatar animal, se escondam seres dotados de uma cultura idêntica à nossa. 
A solução desse dilema foi formulada muitas vezes em termos morais: consciente do dano que é obrigado a causar a um de seus semeIhantes, o caçador se empenharia em todos os tipos de compensações simbólicas para aliviar sua má consciência e precaver-se das conseqüências que seu ato não poderia deixar de acarretar. A antiguidade é o mérito dessa explicação funcional. Frazer a propõe desde o começo do século para dar conta do que chamava ritos expiatórios em relação aos animais caçados (Frazer 1922: caps. 53 e 54). A etnografia russa do pré-guerra invocou-a igualmente para explicar os ritos de caça siberianos, em particular a obrigação dos homens de alimentar os ongon, aquela categoria de entidades que engloba tanto figuras em forma animal ou humana quanto animais selvagens de estimação: alimentando tais substitutos de caça acolhidos no lar, o caçador assim desviaria a vingança que está consciente de merecer pelas violências que exerce contra a caça (Zelenin 1952). Em um tom similar, embora sem menção explícita à Sibéria, Philippe Erikson (1984) propôs considerar a criação de animais selvagens na A mazônia como uma prática compensatória, reparação simbólica do dano infligido aos genitores por meio da adoção e sustento dos filhotes da caça. Certamente os povos da região obedecem de antemão a uma ética da caça - não matar mais animais além do necessário, comportar-se com respeito para com a caça, não fazê-la sofrer à toa etc. Vários deles oferecem ainda contrapartidas rituais aos animais ou aos espíritos que os representam na forma de ofertas de tabaco, comida ou mesmo almas. Entretanto, em um universo cultural em que a reciprocidade seria um valor cardinal, tais dispositivos não chegariam a suprimir completamente o "mal-estar conceitual" que o caçador experimentaria diante da retirada unilateral de uma vida. Daí a função de justificação da criação de animais: acolhendo os órfãos, não poupando esforços para garantir-lhes os cuidados necessários à sobrevivência, os índios anulariam o ato de violência que essa adoção torna necessário.

Do mesmo modo, é a má consciência do caçador que Stephen HughJ ones invoca para interpretar a atitude ambivalente dos índios da Amazônia em relação à carne de caça: a carne é desejável, mas é perigosa quando consumida em excesso ou de modo indiscriminado. Uma densa rede de interdições e prescrições alimentares, de procedimentos rituais de descontaminação e de dispositivos semânticos de ocultação deve atenuar, então, as conseqüências da triste obrigação em que se encontram os homens de destruir vidas animais para reproduzir a sua. Segundo Hugh-J ones, essa mistura de reconciliação e duplicidade com relação ao matar e consumir o animal não seria própria aos índios da Amazônia; 
refletiria um traço universal da natureza humana e, nesse sentido, o comportamento dos ameríndios nada teria de exótico ou arcaico, mas seria inteiramente homólogo à má consciência que os ocidentais experimentam atualmente diante da carne dos açougues (Hugh-J ones 1996).

$N$ ão nego absolutamente que a necessidade de matar animais para se alimentar possa suscitar sentimentos ambivalentes. Bem no início de minha estada entre os Achuar, eu mesmo tive uma experiência muito viva quando atirei em um animal pela primeira vez na vida, instado por meu companheiro desarmado que não via razão verdadeira para que a espingarda de que tive a idéia ridícula de me prover a fim de completar a panóplia de antropólogo não pudesse servir para matar o macaco que zombava de nós em um galho baixo. É mesmo muito provável que tal ambivalência seja universal, se levarmos em conta os estudos de psicologia cognitiva sobre a construção ontogenética das categorias do vivo. Com efeito, parece que as crianças desenvolvem muito cedo uma espécie de teoria ingênua dos estados mentais, isto é, um saber implícito que lhes permite interpretar os atos e as atitudes dos seres animados em função de certos atributos que imputam a eles, como a intencionalidade ou a capacidade de sentir emoções. Os trabalhos de Susan Carey (Carey 1985; Carey e Spelke 1994), em particular, indicam que a própria animação é percebida como derivada desses atributos, de tal modo que as crianças muito pequenas concebem os humanos e os animais como pertencendo a uma mesma categoria ontológica, formal mente homóloga ao que poderíamos definir como uma pessoa. Só mais tarde emerge a categoria de animal, organizada em grande medida a partir das propriedades que a criança associa às atividades humanas. O último estágio da construção do conceito de objeto vivo ocorre com a junção do domínio das plantas àquele dos animais, no quadro do desenvolvimento de uma teoria ingênua das funções biológicas.

Provavelmente, na idade adulta, preservamos os traços dessa indistinção conceitual originária entre o homem e o animal. Como não reconhecer o estatuto ambíguo dos animais, especialmente dos mamíferos superiores, tão próximos de nós sob tantos aspectos e contudo tão diferentes? Quem nunca atribuiu, ainda que de maneira fugaz, emoções, uma sensibilidade, uma intencionalidade a um animal de estimação? O próprio sofrimento infligido às vezes aos animais não seria um sinal de que percebemos sua natureza como essencialmente equívoca, a meio caminho da humanidade e dos outros objetos do mundo, vivos ou não-vivos? É isso que Luc Ferry (1992:90-91) observa muito justamente, comentando Maupertius: quer se tenha prazer ou não, o espetáculo do sofrimento de 
um animal não pode nos deixar indiferentes pois, evocando o nosso, lembra-nos uma analogia fundamental que as plantas são incapazes de suscitar, mesmo com um grande esforço de imaginação.

Na própria A mazônia muitos sinais atestam uma atitude ambivalente para com os animais caçados. Por exemplo, o emprego bastante comum de eufemismos que dissimulam ou atenuam a violência que se faz a caça sofrer. É raro falar-se de matar animais, e exprime-se a ação de caçar por metáforas que não evocam o matar de maneira direta. Sucede muito freqüentemente não se designar os animais por seu nome no contexto de uma batida de caça, preferindo-se substitutos estereotipados. Sempre no plano terminológico, a caça com zarabatana é claramente diferenciada da caça com lança ou com borduna (e atualmente com espingarda): falase em "soprar pássaros" entre os Achuar, "soprar a caça" entre os Tukano, ou mesmo "ir soprar" entre os Huaorani, atenuando, assim, por essas metonímias instrumentais a ligação de causa e efeito entre a ação do caçador e seu resultado (Hugh-J ones 1996:137; Rival 1996:155). Enfim, o tema da vingança dos animais caçados é muito comum, embora a ampli tude das represálias a eles imputadas e as medidas de precaução variem consideravelmente segundo as culturas. Se o animal de caça sente algum motivo para se vingar, então os ameríndios têm uma consciência bastante clara de que a sorte que lhe impõem não é inteiramente normal.

Incontestavelmente, todas essas razões advogam pela consideração da ambivalência das atitudes do caçador amazônico ao matar um animal. Mas daí a Ihe imputar um sentimento de má consciência e a derivar desta os comportamentos na realidade muito diversos que caracterizam o tratamento da caça na região, há um passo que me recuso a dar. Ainda que formulada com muitas nuanças, a tese da má consciência, com efeito, oferece mais inconvenientes que vantagens. Primeiramente, porque isso implica projetar sobre culturas muito diferentes da nossa uma forma de sensibilidade com relação aos animais que talvez experimentemos espontaneamente, mas que sabemos ser o produto de uma evolução específica das práticas e das mentalidades, traçada em toda a sua complexidade por historiadores como Robert Delort (1984) ou Keith Thomas (1983). Não tivemos sempre má consciência em face do sofrimento dos animais, e muitos turistas ingleses que ficam indignados com a barbárie da tourada provavelmente ignoram que o ataque de molossos a um touro preso (bull-baiting) era um espetáculo apreciado por todas as classes sociais na Inglaterra do século XVIII.

A lém disso, a má consciência implica um dilema moral, e portanto um quadro ético em cujo seio se desenvolve um sistema mais ou menos 
explícito de direitos, obrigações e valores. Seria preciso então supor que esse quadro ético seja universal e que se coloque, sempre e em toda parte, o mesmo tipo de dilema quando se mata um animal. É esquecer-se que nossa própria concepção sobre o que fundamenta a distinção entre o homem e o animal sofreu uma profunda mutação ao fim do século XVIII, quando pensadores como Rousseau e Kant definiram a humanidade pela liberdade, ou seja, pela faculdade de subtrair-se às determinações instintivas. Ora, o humanismo moderno baseia-se exatamente nessa idéia para definir nossos deveres para com os animais: é porque alguns dentre eles são dotados da capacidade de agir com vistas a um fim consciente - à diferença das plantas ou das bactérias - e porque essa atitude apresenta analogias com o livre-arbítrio que nos singulariza, que nós nos devemos o respeito a eles, ou seja, devemos respeitar neles aquilo que nos leva a nos respeitar a nós mesmos ${ }^{2}$. O sentimento de culpa gerado pela morte de um animal é então alimentado aqui pela consciência de uma perturbadora proximidade entre a negação de um direito à vida e a negação de um direito à liberdade. Parece-me duvidoso que os índios da Amazônia tenham um raciocínio moral idêntico.

Parece-me duvidoso, inclusive, que se possa dizer de uma disposição ética qualquer que ela seja universal, tanto a normatividade nesse domínio depende das escol has culturais³. Poderíamos nos indagar, por exemplo, sobre a natureza dos preceitos fundamentais que uma "moral amazônica" compreenderia, por vezes no sentido em que se fala de uma "moral judaico-cristã". Vejo unicamente dois preceitos que seriam incontestáveis em toda a região: a condenação da avareza e a exigência do controle de si. O primeiro deriva menos de uma obsessão pela reciprocidade que da obrigação de ser generoso com o próximo e de um certo desdém com relação à acumulação de bens materiais. Quanto ao segundo, cuja marca pode ser vista em toda parte nas condutas de autocontenção - a abstinência sexual, a valorização da frugalidade, da aptidão para a vigília e da resistência física, a prática da flagelação e de banhos em água gelada, ou o uso de purgantes e eméticos - , ele manifesta menos uma transferência para si do desejo recalcado de exercer uma dominação sobre outrem que a necessidade de afirmar a todo momento a superioridade de uma autodisciplina livremente consentida sobre um controle social passivamente sofrido. De resto, existe uma variação muito grande, segundo as culturas amazônicas, quanto ao grau de tolerância diante de determinados comportamentos individuais ou coletivos. $\mathrm{O}$ ardil, a mentira e a dissimulação podem ser considerados meios legítimos ou, ao contrário, condenáveis para se atingir os próprios fins; a capacidade de exer- 
cer violências físicas pode aparecer como uma dimensão da virtù masculina ou, ao contrário, suscitar um verdadeiro horror; a crueldade pode despertar a reprovação ou constituir um elemento julgado indispensável dos rituais de iniciação ou do tratamento dos cativos (ver, p. ex., Clastres 1973). Em resumo, seria bem difícil atribuir aos povos da região um conjunto de disposições morais partilhadas. Seria então legítimo afirmar que a má consciência, isto é, o produto de um conflito moral, seja ali deslanchada como entre nós pelas mesmas circunstâncias? Recusar a universalidade da má consciência em face do consumo de um animal apresenta, certamente, o inconveniente de fazer os índios da Amazônia parecerem muito diferentes de nós. Não é, porém, ceder a um relativismo cultural desenfreado pensar que eles o são de fato: afinal de contas, não consideramos os animais como pessoas - exceto como pessoas jurídicas, para uma minoria - e nosso antropocentrismo, conforme vimos, possui raízes muito diferentes do deles.

Enfim, e como Hugh-J ones (1996:147) observa muito justamente, mesmo no seio das sociedades tribais, há grande variabilidade individual de preferências alimentares e de atitudes para com os animais. $\mathrm{O}$ argumento da má consciência permitiria atribuir essa diversidade de condutas às morais que cada um forja por conta própria em função de sua sensibilidade e temperamento. Se este fosse realmente o caso, reinaria nesse domínio a mais completa arbitrariedade. Ora, a inegável variabilidade individual exprime-se, contudo, no seio de um esquema geral de comportamento partilhado por todos os membros de uma cultura, e que difere de uma cultura para outra. Acontece hoje, por exemplo, de os Achuar comerem animais tradicionalmente proibidos. $M$ as tal relaxamento tem limites, e a idéia de consumir certas espécies continua a suscitar uma sincera repugnância. Comprova-o a aventura de um jovem A chuar em visita aos Quéchua: tendo comido com grande prazer uma carne que Ihe fizeram acreditar ser uma cotia, ele foi tomado subitamente de náusea e obrigado a ir vomitar quando os anfitriões zombeteiros - bem informados acerca dos hábitos alimentares de seus vizinhos tribais - revelaram-lhe que, na verdade, se tratava, que abominação, de um gambá. A despeito das aparências, também entre nós é grande a normatividade. Decerto, e apesar do atributo totêmico que os ingleses nos conferem, alguns franceses não comem rã nunca; porém, não conheço nenhum que coma cobra ordinariamente. Comer ou não comer rãs depende da variabilidade das escolhas individuais no interior de uma norma aceita - ou da acessibilidade do animal; não comer cobras depende de um interdito cultural, que é implícito mas nem por isso deixa de orientar nossas decisões. Insistir 
sobre as determinações morais e individuais das condutas talvez permita restituir toda a complexidade do real; seria também tornar penosa, se não impossível, a ambição antropológica de dar um sentido a comportamentos disparatados, mas que apresentam certa coerência quando tomados todos juntos no seio de uma determinada comunidade.

O "mal-estar conceitual" invocado por Erikson para qualificar o estado de espírito do caçador amazônico parece-me, portanto, preferível à má consciência, pelo menos em nome dos argumentos cognitivos já considerados. Não estou contudo persuadido de que a adoção de filhotes de caça, na Amazônia, possa ser considerada sempre e em toda parte como uma forma de compensação destinada a dissipar esse embaraço psicológico. Com efeito, é comum se tratar os humanos de maneira idêntica: nas guerras inter e intratribais, as mulheres e os filhos dos inimigos mortos são capturados e integrados às famílias dos vencedores, geralmente sem reservas nem discriminação. Ora, a julgar pelo exemplo jívaro, esta prática não procede absolutamente do desejo de fornecer aos inimigos uma contrapartida pelas vidas que Ihes foram tiradas; pelo contrário, o rapto de crianças é a expressão de uma filosofia da predação, segundo a qual a apropriação junto a outrem de substâncias, identidades e pessoas é a condição necessária para a perpetuação do si (Descola 1993a: cap. 17; 1993b). Que, a despeito dos benefícios simbólicos e sociais que proporciona, o homicídio de um inimigo possa suscitar sentimentos ambivalentes, os J ívaro não discordariam, e dizem do guerreiro vitorioso que ele próprio está um pouco morto e é perigoso para os seus em função de seu ato, devendo, por essa razão, submeter-se a um tratamento ritual longo e rigoroso antes de retomar seu lugar entre os vivos ordinários. O exemplo jívaro está longe de ser único: muitas sociedades amazônicas entendem que o homicida, penetrado pelo sangue ou pela alma da vítima, sofre uma transformação corporal suficientemente perigosa para acarretar a morte caso não cumpra rápido os ritos adequados ${ }^{4}$. Em todos esses casos, as conseqüências da violência contra outrem voltam-se então contra si e de modo algum implicam a idéia de que se possa cair em dívida. O que vale para a morte de um homem deveria valer a fortiori para a morte de um animal, e isso me parece excluir a hipótese de que, em um bom número de sociedades amazônicas, a domesticação da caça possa ser aparentada com uma forma de compensação.

Fundamentar a relação com os animais caçados na generalização de um dilema moral é proibir-se de compreender as modalidades muito diversas que a relação entre caçadores e presas pode assumir na Amazônia. Com efeito, uma vez que se conferem propriedades culturais aos ani- 
mais, as relações estabelecidas com eles são antes de tudo relações de pessoa a pessoa, ou seja, são relações sociais, e me parece que é esse aspecto social que deve ser privilegiado na análise ${ }^{5}$. Ora, no interior de um quadro geral relativamente uniforme na escala da Amazônia, a sociologia da relação com os animais pode ser dita de vários modos. Esse quadro geral, como já foi observado há muito tempo, é aquele de uma aliança contratual que vincula os humanos aos animais ou, às vezes, a seus representantes (Zerries 1954). M ais recentemente, percebeu-se que muito freqüentemente essa aliança era conceituada sob a forma de uma relação entre afins e que era marcada pela mesma rede de obrigações que aquela característica das relações entre parentes por aliança (Descola 1983; Erikson 1984)6.

Representar os animais caçados como afins não tem nada de surpreendente no contexto amazônico. A predominância, aí, do cognatismo e dos sistemas de parentesco de tipo dravidiano tem como efeito a redução do registro das categorias sociais a uma grande dicotomia organizada em torno do eixo que separa a consangüinidade da afinidade. Dada a diversidade das situações em que devem ser empregadas, essas duas categorias se tornam operadores lógicos relativamente abstratos que permitem denotar relações mais englobantes do que aquelas que definem os laços de consangüinidade e afinidade efetivamente atestados no seio do grupo local. É esse particularmente o caso da afinidade, relação instável e freqüentemente conflituosa, que oferece então um suporte metafórico excelente para qualificar as relações com o exterior, especialmente com os inimigos próximos ou longínquos. Além disso, o dualismo engendrado pelo sistema dravidiano é temperado por uma tendência muito geral para manipular as atitudes e as terminologias de parentesco, de modo a minimizar os laços de afinidade no seio do grupo local em proveito de uma consangüinidade ideal, e a sublinhá-los, contrariamente, nas relações com o exterior. A relação de afinidade torna-se, por conseguinte, cada vez mais abstrata e esquemática, à medida que se afasta do centro onde efetivamente ela orienta a aliança de casamento (Viveiros de Castro 1993; para o caso jívaro, Taylor 1983 e Descola 1993b). Seria previsível que essa categoria genérica da afinidade servisse de molde mental para a conceituação da relação com a caça, assim como seria previsível que os animais de estimação fossem considerados antes como consangüíneos, a exemplo dos filhos dos inimigos raptados para serem integrados à família do homicida de seus pais. $O$ animal de caça apresenta-se assim na Amazônia, seja como um alter ego em posição de exterioridade quando é caçado, seja como demasiado idêntico a si para 
ser comido quando domesticado - uma distinção de estatuto que formulei recentemente (Descola 1994) nos termos de uma homologia estrutural clássica:

caça : animais de estimação : : inimigos : crianças cativas : : afins : consangüíneos

Todavia, no âmbito desse quadro muito geral, coexistem vários sistemas de relações mais particularizados. Posso discernir pelo menos três, que chamarei reciprocidade, predação e dádiva, e que correspondem a três modalidades lógicas, e também sociológicas, de integrar a oposição universal entre eu e outrem. A reciprocidade quer que toda vida animal seja compensada (freqüentemente por uma ou outra forma de vitalidade humana); a predação implica que nenhuma contrapartida seja oferecida pelos humanos contra uma vida animal; finalmente, a dádiva significa que os animais oferecem sua vida aos humanos de maneira deliberada e sem nada esperar em troca7.

Os Desana, grupo de língua tukano do noroeste amazônico, fornecem a mais clássica ilustração etnográfica do modelo da reciprocidade (Reichel-Dolmatoff 1976). Esta é aqui fundada sobre um princípio de equivalência entre homens e animais no seio de um cosmos concebido como um circuito fechado homeostático. $\mathrm{N}$ a medida em que a energia vital genérica presente na biosfera existe em quantidade finita, as trocas internas devem ser organizadas de modo a que as retiradas efetuadas pelos homens, especialmente por ocasião da caça, possam ser reinjetadas no circuito. $O$ feedback energético é assegurado, principalmente, pelo retorno das almas dos defuntos ao Senhor dos Animais que as converte em caça. Entre os Desana, portanto, os humanos e os animais são substitutos uns dos outros e possuem um estatuto equivalente na comunidade de energia do mundo vivo; juntos, eles contribuem para manter o equilíbrio dos fluxos, já que suas funções são reversíveis nessa busca de uma homeóstase perfeita.

O modelo da predação é particularmente manifesto no caso das tribos J ívaro, que não oferecem nenhuma compensação pela vida da caça. Certamente, às vezes acontece que os excessos sejam punidos: os Senhores dos A nimais podem aplicar represálias - sob a forma de picadas de cobra ou acidentes provocados na floresta - àqueles que teriam violado as regras de respeito e moderação relativas à atividade de caça; mas não se trata em absoluto de um processo regular de troca voluntária fundado sobre uma paridade dos parceiros. Diferentemente dos Tukano, aqui nenhuma idéia de circulação de energia vem conferir uma aparência de eqüidade a essa atitude predatória para com os animais de caça, dissimu- 
lada sem precauções excessivas por trás de uma simbólica da aliança na qual uma das partes jamais honra suas obrigações.

Finalmente, o modelo da dádiva é bem ilustrado pelas tribos Aruaque que habitam o piemonte amazônico dos Andes centrais do Peru (Weiss 1975; Renard-Casevitz 1972). As espécies caçadas, particularmente os pássaros, dependem, quanto ao essencial, de uma raça de bons espíritos que os A ruaque chamam de "nossa gente", ou "nossos congêneres", e que são reputados de demonstrarem boa disposição para com os índios. Matar pássaros é assimilado a uma metempsicose provocada: depois de o caçador ter-Ihe pedido sua "roupa", o pássaro voluntariamente oferece seu invólucro carnal à flecha, preservando seu duplo imaterial que se reencarna imediatamente em um corpo idêntico. Não se incorre então em nenhum dano, e este ato de benevolência não pede contrapartida. Com efeito, no plano ontológico, os bons espíritos e seus avatares animais são idênticos aos humanos: são considerados como parentes muito próximos, consangüíneos ou afins segundo as espécies, de tal modo que a dádiva de seus despojos é percebida como uma simples prova do dever de generosidade que se impõe entre pessoas estreitamente próximas pelo parentesco.

Em que esses modelos de comportamento diante dos animais manifestam uma dimensão sociológica? J ustamente no fato de revelarem uma atitude mais geral perante outrem, humanos e não-humanos aí confundidos totalmente, típica de cada uma das culturas em questão. Admito de bom grado que a práxis de uma sociedade não poderia ser reduzida a um esquema único e que pertence à utopia uma comunidade na qual as condutas fossem regidas exclusivamente pela oblação ou captura. O observador que mergulha por muito tempo em uma cultura não pode contudo deixar de perceber que seus membros orientam seus atos em função de um pequeno número de valores que muito freqüentemente permanecem não formulados. É sempre arriscado colocar uma etiqueta sobre esses valores, mas esta é a servidão de todo procedimento analítico e a condição para explicitar o que poderia ser chamado de estilo distintivo, ou ethos de uma sociedade.

Assim, a organização social dos Desana, como das outras tribos Tukano do Vaupés, é fundada sobre uma lógica da paridade completamente homóloga àquela que rege as relações com os animais. A exogamia lingüística e a rede de circulação dos artefatos geram uma situação na qual cada tribo, cada grupo local, se percebe como um elemento no seio de um metassistema regional, elemento que deve sua perenidade material e ideal às trocas regradas com as outras partes do todo (J ackson 
1983; Hugh-J ones 1993). Inversamente, nos grupos J ívaro, o estado de guerra generalizado exprime a necessidade de compensar cada morte pela captura junto a outrem de identidades reais - o rapto de mulheres e crianças - ou virtuais - as cabeças-troféus, peças centrais de um dispositivo ritual de produção de filhos (Taylor 1993; Descola 1993b). Certamente, a obrigação da vingança acaba por restaurar o equilíbrio; no entanto, compreender-se-á sem dificuldade que as represálias dos inimigos sejam uma conseqüência prevista, mas não ativamente procurada, dos atos de violência cometidos contra eles. A predação mútua é assim um resultado não intencional de uma rejeição geral da reciprocidade, mais do que uma troca deliberada de vidas humanas através de um comércio belicoso. Por fim, embora a lógica da dádiva seja mais difícil de se aplicar de modo sistemático nas peripécias cotidianas da vida social, é impressionante verificar a que ponto os grupos Aruaque subandinos se esforçam para minimizar em seu seio as oposições entre o eu e o outro. É o que testemunham de modo particularmente claro os Amuesha, que, a exemplo de A ristóteles, consideram que o amor constitui a fonte e o princípio de existência de tudo o que há. Distinguem dois tipos de amor: muereñets significa a dádiva de si na criação da vida e caracteriza a atitude das divindades e dos líderes religiosos em uma relação assimétrica; enquanto morrenteñets denota o amor mútuo indispensável a qualquer sociabilidade e se exprime por uma generosidade permanente, isenta de cálculo e previsão de retribuição (Santos Granero 1994). Como não se impressionar aqui, também, com a estreita correspondência entre o tratamento da caça e o tratamento dos humanos?

Reciprocidade, predação e dádiva constituem três formas de relação entre os humanos e os animais que, ao menos em duas delas, parecem dissimular, sob a aparência de uma relação social livremente consentida, a violência efetiva exercida pelo caçador contra a caça. Errar-se-ia, porém, vendo aí uma astúcia da razão selvagem destinada a tornar suportável a idéia de matar seres dos quais tudo nos aproxima, em suma, uma forma de hipocrisia coletiva e inconsciente que transformaria a necessidade de destruir e incorporar o vivo em uma mentira partilhada por aqueles que aí estão enredados e por suas vítimas. Errar-se-ia, primeiramente, porque certas sociedades amazônicas, como os J ívaro, não experimentam absolutamente a necessidade de dissimular para si mesmas a natureza assimétrica de sua relação com a caça. A má-fé que manifestam ao fingirem ter com ela uma relação igualitária de afinidade - sem contudo jamais satisfazerem as obrigações de reciprocidade que uma tal relação implica - é comandada pelo medo de vê-la desaparecer, não por um sen- 
timento qualquer de culpa8. A violência, aqui, é manifesta e livremente assumida. Errar-se-ia ainda porque uma tal perspectiva coloca em dúvida que os ameríndios possam acreditar suficientemente no que dizem para agir de acordo com o que pensam. Ora, levando-se a sério o que enunciam os Desana, os A shaninka, os M atsiguenga ou os A muesha, deve-se admitir que matar um animal que eu creio que vá reencarnar imediatamente, não é matar, mas ser o agente de uma metamorfose; igualmente, matar um animal que eu creio poder substituir ao fim por almas humanas, é menos matar do que aceitar o adiantamento de uma vida. A violência desaparece aqui não porque seja recalcada, mas porque não poderia ser efetiva em cosmologias concebidas como sistemas fechados nos quais a conservação do movimento dos seres e das coisas exige que as partes troquem constantemente de posição.

Tradução de Tânia Stolze Lima

Recebido em 19 de maio de 1997

A provado em 16 de junho de 1997

Philippe Descola é diretor de estudos da École des Hautes Études en Sciences Sociales e membro do Laboratoire d'Anthropologie Sociale, Paris. Recentemente, publicou Les Lances du Crépuscule (1994) e, com G. Pálsson, Nature and Society (1996). 


\section{Notas}

1 Quanto ao tratamento do animal, ver, por exemplo, a diferença entre a caça na Europa meridional (Bernardina 1996) e a caça de tradição germânica (Hell 1994).

2 Tomo de Luc Ferry (1992:100-101) esta apresentação da posição humanista.

3 É claro que isso não quer dizer que uma antropologia moral universal não seja desejável: o relativismo que invoco aqui provém da constatação empírica, não da afirmação de um valor positivo.

4 Ver, por exemplo, para os Yanomami (Albert 1985); para os A raweté (Viveiros de Castro 1992); para os Krahó (Carneiro da Cunha 1978); para os A pinayé (Da Matta 1976).

5 O fato de ser formulada em termos abstratos, não torna uma relação social menos irrigada por um conjunto de afetos, mas, se o procedimento analítico o reconhece facilmente, isso não implica que se seja obrigado a dar a essa dimensão um papel distintivo ou explicativo.

6 Roberte Hamayon (1990) chegou a conclusões similares para a Sibéria.

7 Também Erikson (1984:108-113) isola na Amazônia três maneiras de resolver o "mal-estar conceitual" do caçador: pela dádiva, pela negociação e pela aliança. Segundo ele, tais tentativas seriam pouco satisfatórias, por deixarem subsistir uma parte de culpabilidade; daí a criação de filhotes da caça. Parece-me, contudo, que, à diferença das três modalidades que eu proponho, as soluções de Erikson não se situam em um mesmo plano analítico: a negociação é englobada pela reciprocidade, visto que é esta que constitui sua condição prática, enquanto a aliança é englobante, já que forma o quadro geral da relação de afinidade [relation affinale] com o animal de caça.

8 Poder-se-ia dizer o mesmo dos Yanomami (Albert 1985:326-335), que vêem a caça de duplos animais dos humanos como uma forma de predação contra comunidades longínquas; ou dos Araweté (Viveiros de Castro 1986:206-209), que colocam a caça e a guerra sob o mesmo registro de atividades desejáveis. 


\section{Referências bibliográficas}

ALBERT, B. 1985. Temps du Sang, Temps des Cendres. Représentation de la Maladie, Système Rituel et Espace Politique chez les Yanomami du Sud-est (Amazonie Brésilienne). Tese de Doutorado, Paris-X. . 1993. “L'Or Cannibale et la Chute du Ciel. Une Critique Chamanique de l'Économie Politique de la Nature (Yanomami, Brésil)". L'Homme, 126-128:349-378.

ÅRHEM, K. 1996. “The Cosmic Food Web: Human-Nature Relatedness in the Northwest Amazon". In: P. Descola e G. Pálsson (orgs.), Nature and Society: Anthropological Perspectives. London: Routledge. pp. 185204.

BALÉE, W. 1993. “Indigenous Transformations of Amazonian Forests: An Example from Maranhão, Brazil". L'Homme, 126-128:231-254.

BERNARDINA, S. Dalla. 1996. L'Utopie de la Nature. Chasseurs, Écologistes et Touristes. Paris: Imago.

CAREY, S. 1985. Conceptual Change in Childhood. Cambridge, Mass.: Bradford Books for the MIT Press. e SPELKE, E. 1994. “Domain-Specific Knowledge and Conceptual Change". In: L. Hirschfeld e S. A. Gelman (orgs.), Mapping the Mind. Domain Specificity in Cognition and Culture. Cambridge: Cambridge University Press. pp. 169-200.

CARNEIRO DA CUNHA, M. 1978. Os Mortos e os Outros. Uma A nálise do Sistema Funerário e da Noção de Pessoa entre os Índios Krahó. São Paulo: Editora Hucitec.

CLASTRES, P. 1973. “De la Torture dans les Sociétés Primitives". L'Homme, 13(3):114-120.
DA MATTA, R. 1976. Um M undo Dividido. A Estrutura Social dos Índios Apinayé. Petrópolis, RJ: Editora Vozes.

DELORT, R. 1984. Les Animaux Ont une Histoire. Paris: Le Seuil.

DESCOLA, P. 1983. “Le J ardin de Colibri. Procès de Travail et Catégorizations Sexuelles chez les Achuar de I'Equateur". L'Homme, 23(1):61-89. 1985. “De I'Indien Naturalisé à I'Indien Naturaliste: Sociétés Amazoniennes sous le Regard de I'Occident". In: A. Cadoret (org.), Protection de la Nature. Histoire et I déologie. Paris: L'Harmattan. pp. 221235.

1986. La Nature Domestique. Symbolisme et Praxis dans I'Écologie des Achuar. Paris: Editions de la $M$ aison des Sciences de I'H omme. . 1993a. Les Lances du Crépuscule. Relations J ivaros. Haute A mazonie. Paris: Plon. . 1993b. “Les A ffinités Sélectives. Alliance, Guerre et Prédation dans I'Ensemble J ivaro". L'Homme, 126128:171-190.

. 1994. “Pourquoi les Indiens d'Amazonie n'Ont-Ils pas Domestiqué le Pécari? Généalogie des Objets et A nthropologie de l'Objectivation". In: B. Latour e P. Lemonnier (orgs.), De la Préhistoire aux M issiles Balistiques. L'Intelligence Sociale des Techniques. Paris: La Découverte. pp. 329-344.

ERIKSON, P. 1984. “De I'A pprivoisement à l'A pprovisionnement: Chasse, Alliance et Familiarisation en Amazonie A mérindienne". Techniques et Cultures, 9:105-140.

FERRY, L. 1992. Le Nouvel Ordre Écolo- 
gique. L'Arbre, l'A nimal et l'Homme. Paris: Grasset.

FRAZER, J. G. 1922. The Golden Bough. A Study in Magic and Religion (Abridged Edition). London: MacMillan.

GRENAND, P. 1980. Introduction à I'Étude de I'Univers Wayãpi: EthnoÉcologie des Indiens du Haut-Oyapock (Guyane Française). Paris: SELAF/CNRS.

HAM AYON, Roberte. 1990. La Chasse à l'Âme. Esquisse d'une Théorie du Chamanisme Sibérien. Nanterre: Société d'Ethnologie.

HELL, B. 1994. Le Sang Noir. Chasse et Mythes du Sauvage en Europe. Paris: Flammarion.

HUGH-J ONES, S. 1993. “Clear Descent or Ambiguous Houses? A Reexamination of Tukanoan Social Organization". L'H omme, 126-128:95-120. . 1996. “Bonnes Raisons ou Mauvaise Conscience? De l'A mbivalence de Certains Amazoniens envers la C onsommation de Viande". Terrains, 26:123-148.

J ACKSON, J . 1983. The Fish People. Linguistic Exogamy and Tukanoan Identity in the Northwest A mazon. Cambridge: Cambridge University Press.

JARA, F. 1991. El Camino del Kumu: Ecología y Ritual entre los A kurió de Surinam. Utrecht: ISOR.

REGAN, T. 1983. The Case for A nimal Rights. Berkeley: University of California Press.

REICHEL-DOLMATOFF, G. 1976. Amazonian Cosmos. The Sexual and Religious Symbolism of the Tukano Indians. Chicago: The University of Chicago Press.
RENARD-CASEVITZ, F. M. 1972. “Les Matsiguenga". Journal de la Société des Américanistes de Paris, 61:215-253.

. 1991. Le Banquet Masqué. Une Mythologie de l'Étranger chez les Indiens M atsiguenga. Paris: Lierre $\&$ Coudrier.

RIVAL, L. 1996. “Blowpipes and Spears: The Social Significance of Huaorani Technological Choices". In: P. Descola e G. Pálsson (orgs.), Nature an Society: Anthropological Perspectives. London: Routledge. pp. 145164.

SANTOS GRANERO, F. 1994. El Poder del Amor. Poder, Conocimiento y M oralidad entre los A muesha de la Selva Central del Perú. Quito: Ediciones Abya-Yala.

SINGER, P. 1989. A nimal Liberation. New York: Random House.

TAYLOR, A. C. 1983. "The Marriage AIliance and its Structural Variations in J ivaroan Societies". Social Science Information, 22(3):331-353.

. 1993. “Les Bons Ennemis et les M auvais Parents. Le Traitement de I'Alliance dans les Rituels de Chasse aux Têtes des Shuar (J ivaro) de I'Equateur". In: E. Copet-Rougier e F. Héritier-Augé (orgs.), Les Compléxités de I'Alliance: IV. Economie, Politiques et Fondements Symboliques. Paris: Editions des Archives Contemporaines. pp. 73-105.

THOMAS, K. 1983. Man and the Natural World. Changing Atitudes in England (1500-1800). London: Allen Lane.

VAN DER hAMMEN, M. C. 1992. El Manejo del Mundo. Naturaleza y Sociedad entre los Yukunas de la 
Amazonia Colombiana. Bogotá: Tropenbos.

VIVEIROS DE CASTRO, E. 1986. Araweté. Os Deuses Canibais. Rio de J aneiro: J orge Zahar/A npocs.

. 1992. From the Enemy's Point of View. Humanity and Divinity in an Amazonian Society. Chicago/London: The University of Chicago Press.

. 1993. "Alguns Aspectos da Afinidade no Dravidianato A mazônico". In: M. Carneiro da Cunha e E. Viveiros de Castro (orgs.), Amazônia: Etnologia e História Indígena. São Paulo: NHII/USP. pp. 149-210.

. 1996. "Os Pronomes Cosmológicos e o Perspectivismo Ameríndio". Mana: Estudos de Antropologia Social, 2(2):115-144.

WEISS, G. 1975. Campa Cosmology. The World of a Forest Tribe in South America. N ew York: American M useum of Natural History.

ZELENIN, D. 1952. Le Culte des Idoles en Sibérie. Paris: Payot.

ZERRIES, O. 1954. Wild- und Bushgeister in Südamerika. Eine Untersuchung J ägerzeitlicher Phänomene im Kulturbild Südamerikanisher Indianer. Wiesbaden: Studien zur Kulturkunde, 11(2). 


\section{Resumo}

Uma certa tradição antropológica tende a interpretar a simbólica da caça como uma maneira de exprimir a ambivalência, até mesmo a má consciência, que todos os humanos sentiriam ao matarem animais. Se essa interpretação parece legítima no quadro das sociedades modernas, marcadas desde o século XIX por uma evolução profunda das sensibilidades nesse domínio, ela não parece sê-lo para as sociedades prémodernas, sobre as quais se pode duvidar que partilhem a mesma moral que os cidadãos euro-americanos do fim do século XX. O exemplo do tratamento da caça na Amazônia indígena mostra que a relação com o animal ali é menos determinada por uma gama de sentimentos universais que por esquemas de comportamento enraizados nos sistemas cosmológicos, ontológicos e sociológicos característicos dessa área cultural.

\section{Abstract}

A certain anthropological tradition tends to interpret the symbolism of hunting as a way of expressing the ambivalence, or even the troubled conscience, that all humans are supposed to feel upon killing animals. While this interpretation appears legitimate in the framework of modern societies, marked since the $19^{\text {th }}$ century by a profound evolution in the sensitivities pertaining to this domain, the same does not appear to be true for pre-modern societies, who may very well not share the same morals as late 20th-century EuroAmerican citizens. The way indigenous peoples deal with hunting in the Amazon illustrates how the relationship to animals there is determined less by a range of universal feelings than by behavioral schemata rooted in this cultural area's characteristic cosmological, ontological, and sociological systems. 